\title{
The effect of certolizumab treatment on insulin resistance, lipid parameters and cardiovascular risk in patients with ankylosing spondylitis
}

\author{
hasan göğebakan ${ }^{1}$ and gözde yıldırım cetin ${ }^{2}$ \\ ${ }^{1}$ Affiliation not available \\ ${ }^{2}$ Department of Internal Medicine, Division of Rheumatology, Kahramanmaras Sutcu \\ Imam University, Kahramanmaraş, Turkey
}

May 20, 2021

\begin{abstract}
Aims: To evaluate the effects of certolizumab treatment on insulin resistance (IR), lipid parameters, and cardiovascular (CV) risk in patients with ankylosing spondylitis (AS). Methods: This prospective study included 80 consecutive patients with AS (52 males, 28 females) and 74 control subjects (48 males, 26 feemales). The AS patients and control group were compared in respect of basal values. All AS patients with active disease were treated with certolizumab. Biochemical profiles were obtained before and after 24 weeks of certolizumab treatment. Homeostatic model assessment-insulin resistance (HOMA-IR) was used to measure IR and the quantitative insulin sensitivity control index (QUICKI) was used to measure insulin sensitivity. The Framingham equation was used to evaluate CV risk factors. Results: A statistically significant increase was determined in total cholesterol (TC), high-density lipoprotein cholesterol (HDL-C), and triglyceride (TG) values after 24 weeks of certolizumab treatment. No statistically significant change was determined in the plasma atherogenic index (PAI) and low-density lipoprotein cholesterol (LDL-C) values. A statistically significant decrease was determined in HOMA-IR and an increase in QUICKI. When the Framingham risk scoring was compared with the baseline values, a statistically significant decrease in risk was found at week 24. Conclusions: Certolizumab therapy was associated with a significant increase in HDL-C, TC, and TG levels without any significant change in PAI and LDL-C, and was determined to increase insulin sensitivity and lower insulin resistance. There was also a significant reduction in SBP and 10-year Framingham risk scores at 24 weeks after the start of certolizumab therapy.
\end{abstract}

\section{The effect of certolizumab treatment on insulin resistance, lipid parameters and cardiovascular} risk in patients with ankylosing spondylitis

Aims : To evaluate the effects of certolizumab treatment on insulin resistance (IR), lipid parameters, and cardiovascular (CV) risk in patients with ankylosing spondylitis (AS).

Methods: This prospective study included 80 consecutive patients with AS (52 males, 28 females) and 74 control subjects (48 males, 26 feemales). The AS patients and control group were compared in respect of basal values. All AS patients with active disease were treated with certolizumab. Biochemical profiles were obtained before and after 24 weeks of certolizumab treatment. Homeostatic model assessment-insulin resistance (HOMA-IR) was used to measure IR and the quantitative insulin sensitivity control index (QUICKI) was used to measure insulin sensitivity. The Framingham equation was used to evaluate CV risk factors.

Results: A statistically significant increase was determined in total cholesterol (TC), high-density lipoprotein cholesterol (HDL-C), and triglyceride (TG) values after 24 weeks of certolizumab treatment. No statistically significant change was determined in the plasma atherogenic index (PAI) and low-density lipoprotein 
cholesterol (LDL-C) values. A statistically significant decrease was determined in HOMA-IR and an increase in QUICKI. When the Framingham risk scoring was compared with the baseline values, a statistically significant decrease in risk was found at week 24.

Conclusions: Certolizumab therapy was associated with a significant increase in HDL-C, TC, and TG levels without any significant change in PAI and LDL-C, and was determined to increase insulin sensitivity and lower insulin resistance. There was also a significant reduction in SBP and 10-year Framingham risk scores at 24 weeks after the start of certolizumab therapy.

Keywords: Ankylosing spondylitis, Certolizumab, İnsulin resistance, Framingham risk scoring, Lipid parameters.

\section{What's known}

- The increased risk of CV morbidity and mortality among patients with AS is likely to be due to the inflammatory nature of the diseases itself.

- All AS patients should be screened for traditional CV factors and the Framingham risk score should be calculated. A number of studies have shown a reduction in sub-clinical atherosclerosis in AS patients treated with TNF- $\alpha$ inhibitory.

- Studies showing their effects on IR, lipid parameters and CVD risk factors in patients with AS generally included infliximab, etanercept, and adalimumab as TNF- $\alpha$ inhibitory agents. There has been no study showing the effect of certolizumab pegol treatment on these parameters.

\section{What's new}

- Certolizumab pegol therapy was associated with a significant increase in HDL-C, TC, and TG levels without any significant change in PAI and LDL-C. Certolizumab therapy increases insulin sensitivity and lowers insulin resistance.

- There was also a significant reduction in SBP and the 10-year Framingham risk scores at 24 weeks after the start of certolizumab pegol therapy.

- This risk reduction in CVD is an important finding because the most important cause of death for patients with AS is CVD.

\section{Background}

Ankylosing spondylitis (AS) is a chronic inflammatory disease of the axial skeleton characterized by low back pain, progressive spinal stiffness, enthesopathy, peripheral arthritis, and extra-articular symptoms. ${ }^{1}$, which is more common in young adult males (male: female ratio 3-4: 1). ${ }^{2}$ This disease is treated with non-steroidal anti-inflammatory drugs (NSAIDs) and tumor necrosis factor-alpha (TNF- $\alpha$ ) inhibitors. The use of TNF- $\alpha$ inhibitory therapy is becoming increasingly common and has been shown to reduce pain and inflammatory markers by improving quality of life. ${ }^{3}$

In patients with AS, endothelial dysfunction is observed in early disease, which can be combined with traditional cardiovascular disease (CVD) risk factors. ${ }^{4}$ However, the relationship between inflammation, atherosclerosis, vascular dysfunction, and AS is multifactorial and still not fully understood. Disorders in lipid levels, especially low levels of serum high-density lipoprotein cholesterol (HDL-C), increased triglyceride levels (TG), and low-density lipoprotein cholesterol (LDL-C) concentrations have been proven to accelerate atherosclerosis. In some studies, the reduction in HDL-C has been reported more frequently in AS patients than in healthy control subjects. ${ }^{5}$ This may be at least partly responsible for the increased CVD risk in patients with AS.

Increased insulin resistance (IR) is an important risk factor for CVD. ${ }^{6}$ Patients with autoimmune connective tissue diseases have increased IR. ${ }^{7}$ TNF- $\alpha$ inhibitory therapy has effects on metabolism, including improvement in $\mathrm{IR}^{8}$. TNF- $\alpha$ inhibitory therapy facilitates the reduction in plasma glucose by blocking TNF- $\alpha$ and increasing insulin sensitivity ${ }^{9}$. A recent systematic review showed that there was a moderate relationship between homeostatic model assessment-insulin resistance (HOMA-IR), the quantitative insulin-sensitivity 
check index (QUICKI), and the hyperinsulinemic-euglycemic clamp technique, which is considered the 'gold standard' for peripheral insulin sensitivity. ${ }^{10}$ The Framingham risk scoring system is a reliable method used to calculate the 10-year CVD risk . ${ }^{11}$ In a study examining the effects of infliximab treatment with the Framingham equation before and after treatment in patients with AS, a significant decrease in Framingham equation was found after treatment. ${ }^{12}$

To the best of our knowledge, there is no study in the literature showing the effects of certolizumab treatment on IR, lipid parameters, and CVD risk factors in patients with AS. The aim of this study was to evaluate the effects of certolizumab treatment at baseline and at the 24th week of treatment on the risk of IR, lipid parameters, and CVD in patients with AS.

\section{Methods}

This prospective study included all active AS patients who referred to the rheumatology outpatient clinic of Kahramanmaras Sütcü Imam University (KSU) for follow-up between February 2018 and February 2019. These patients were previously diagnosed with AS according to the 1984 New York classification criteria. ${ }^{13}$ This study included 80 patients with AS (52 males and 28 females) and 74 controls (48 males and 26 females) with similar age and sex. The control group consisted of individuals who referred to the rheumatology outpatient clinic of KSU with complaints of arthralgia and myalgia and who did not have any rheumatologic disease based on physical examinations and laboratory findings, who were not diagnosed with any chronic disease previously, who were not receiving any medical therapy.

Disease activity of the AS patients was measured using the Bath Ankylosing Spondylitis Disease Activity Index (BASDAI) method, and TNF- $\alpha$ inhibitor treatment (certolizumab) was started for patients who received NSAID therapy with BASDAI values [?]4 and not in remission. The study exclusion criteria for the AS patients was as follows: history of malignant disease, lupus or myelinating disease, severe kidney or liver disease, a history of hepatitis B or C, plasma fasting blood glucose (FBG) levels $>100 \mathrm{mg} / \mathrm{dL}$, drug use affecting glucose and lipid metabolism, pregnancy and breast feeding, active infection and systemic corticosteroid treatment in the four weeks before the study. Chest X-ray, a tuberculin skin test, and interferon-gamma release test were performed on all AS patients. Certolizumab treatment was started one month after TB prophylaxis was initiated in patients with evidence of latent TB. Certolizumab treatment was administered subcutaneously, with an initial dose of $400 \mathrm{mg}$ given at 0,2 , and 4 weeks, and a maintenance dose of 200 mg administered every two weeks starting at 6 weeks.

In the evaluation of the AS patients before any treatment and the control group, a record was made of age, gender, and body mass index (BMI) $\left(\mathrm{kg} / \mathrm{m}^{2}\right)$. Systolic blood pressure (SBP) and diastolic blood pressure (DBP) were manually measured in the brachial artery by the same physician. After 12 hours of fasting overnight, venous blood samples were taken for the examination of total cholesterol (TC), LDL-C, HDL-C, and TG. The plasma atherogenic index (PAI) was calculated according to the $\log 10$ TG/HDL formula. ${ }^{14}$ In addition to the above-mentioned values, the following data were collected from AS patients prospectively at baseline and at week 24; serum fasting insulin concentration $(\mu \mathrm{IU} / \mathrm{mL}), \mathrm{FBG}(\mathrm{mg} / \mathrm{dL})$, pain severity using a 10-cm visual analogue scale (VASp), morning stiffness duration (minutes), modified Schober test (cm), chest expansion $(\mathrm{cm})$, C-reactive protein levels $(\mathrm{CRP})(\mathrm{mg} / \mathrm{L})$ and erythrocyte sedimentation rate $(\mathrm{ESR})(\mathrm{mm} / \mathrm{h})$. HOMA-IR index model evaluations were used to measure IR. ${ }^{15}$ The HOMA-IR index was calculated as fasting insulin concentration $(\mu \mathrm{IU} / \mathrm{mL}) \times \mathrm{FBG}(\mathrm{mg} / \mathrm{dL}) / 405$, assuming $<2.5$ as the score of normal adults. The QUICKI was calculated using the formula of $1 / \log$ insulin $(\mu \mathrm{U} / \mathrm{mL})+\log$ glucose $(\mathrm{mg} / \mathrm{dL}) .{ }^{16}$ The Framingham equation was used to assess the risk of CVD ${ }^{11}$. The Framingham equation takes into account the following variables: age, sex, SBP, and DBP, serum LDL-C and HDL-C levels, smoking status, and presence/absence of DM.. Functional capacity was assessed using the Bath Ankylosing Spondylitis Disease Function Index (BASFI).

No patient took drugs known to affect glucose, lipid metabolism, or BP. Patients were warned not to make lifestyle changes or use a new drug without permission during the study period. This study was approved by the Ethics Committee of Kahramanmaras Sutcu Imam University Faculty of Medicine (Approval Date: 
November 25, 2017; Approval Number: 2017/17-05) and was conducted in accordance with the Helsinki Declaration of 1975. Informed consent was obtained from all the participants included in the study.

\section{Statistical analysis}

Statistical analyses were performed using the Statistical Package for the Social Sciences software (SPSS for Windows, version 17.0). Conformity of the variables to normal distribution was investigated using visual (histograms, probability plots) and analytical methods (Kolmogorov-Smirnov/Shapiro-Wilk test). The Wilcoxon rank-sum test, or the Independent-samples Student's t-test were applied to continuous variables, as appropriate, to determine whether there was a significant difference between the groups in respect of the characteristics of patients. Results were expressed as median and mean \pm standard deviation (SD) values. Changes observed before and after certolizumab treatment were evaluated using paired samples ttests for normally distributed data and Wilcoxon analyses for data with non-parametric distributions. After treatment, Spearmen correlation analysis was used to establish the relationship between the variables. All p values were 2 -tailed and a value of $\mathrm{p}<0.05$ was considered statistically significant.

\section{Results}

Evaluation was made of a total of 80 consecutive patients with AS, comprising $52(65 \%)$ males and $28(35 \%)$ females, and a control group of 74 healthy individuals comprising $48(64.8 \%)$ males and $26(35.2 \%)$ females. The basal demographic and clinical characteristics of the AS patients and the control group are shown in Table 1. The PAI $(\mathrm{p}=0.004)$ and TG $(\mathrm{p}=0.000)$ values of the AS patients were determined to be statistically significantly higher than those of the control group, and the HDL-C (0.016) value was lower. No statistically significant difference was determined between the groups in respect of age, gender, BMI, TC, LDL-C, SBP and DBP. In the AS patient group, uveitis was determined in $12(15 \%)$ patients, peripheral joint involvement in $17(21.2 \%)$ and inflammatory bowel disease in $6(7.5 \%)$ (Table 1$)$.

A complete biochemical profile and assessments were obtained at the beginning of certolizumab therapy and after 24 weeks of treatment. The results obtained pre and post-treatment are shown below.

Compared to the baseline values, the values obtained after 24 weeks of certolizumab treatment demonstrated a statistically significant decrease in ESR, CRP, BASDAI, BASFI, VASp, ASQoL and Morning Stiffness (minutes) as effects on the disease characteristics of AS patients $(\mathrm{p}=0.000)$, and a statistically significant increase in the modified Schober, and chest expansion values $(\mathrm{p}=0.000)$ (Table 2). Following 24 weeks of certolizumab treatment in AS patients, a statistically significant decrease was determined in FBG $(\mathrm{p}=0.028)$, HOMA-IR $(\mathrm{p}=0.014)$ and serum insulin level $(\mathrm{p}=0.000)$ and a statistically significant increase in QUCKI $(\mathrm{p}=0.004)$ compared to the pre-treatment values. (Table 3$)$.

After 24 weeks of certolizumab treatment, a statistically significant increase was determined in TC, HDL-C, and TG values compared to baseline $(\mathrm{p}=0.000, \mathrm{p}=0.004, \mathrm{p}=0.024$, respectively $)$, and no significant change was determined in LDL-C $(\mathrm{p}=0.065)$ and PAI $(\log 10 \mathrm{TG} / \mathrm{HDL})(\mathrm{p}=0.624)$ values. Compared to the pretreatment values, a statistically significant increase was determined post-treatment in the weight $(\mathrm{p}=0.000)$ and BMI $(\mathrm{p}=0.003)$ values, a decrease in SBP $(\mathrm{p}=0.012)$ and no significant change in DBP $(\mathrm{p}=0.254)$. In the pre and post-treatment comparisons of the Framingham risk score, used to evaluate the 10-year CVD risk, there was determined to be a statistically significant decrease in risk at week $24(\mathrm{p}=0.018)$ (Table 4).

\section{Discussion}

There were four main findings that emerged from this study. First, the PAI and TG values of the AS patients were determined to be higher than those of the healthy control group and the HDL-C value was lower. Second, the ESR, CRP, BASDAI, BASFI, VASp, ASQoL and morning stiffness values were determined to have decreased and the modified Schober and chest expansion values to have increased after 24 weeks of certolizumab treatment. Third was that following 6 months of certolizumab treatment, there was a decrease in the FBG, HOMA-IR and insulin levels and an increase in the QUCKI value. Finally, the fourth significant finding was that after the certolizumab treatment, there was an in increase in weight, BMI, TC HDL-C and 
TG values, a decrease in SBP, and no change in DBP, LDL-C and PAI values. The Framingham risk score, which evaluates the 10-year CVD risk, showed a statistically significant decrease in risk at week 24 .

There is strong evidence that TNF- $\alpha$ inhibitor therapy reduces the incidence of CVD events in patients with rheumatoid arthritis (RA), but there are conflicting results in limited data from patients with AS. ${ }^{17,18}$ In the results reported from the analysis in the Australian Rheumatology Association Database, where patients with RA, psoriatic arthritis (PsA), and AS, which were recently updated, patients who used biological drugs with a TNF- $\alpha$ inhibitor or another mechanism of action also had a decrease in CVD event rates compared with patients with biologically naive inflammatory arthritis, and it was shown that the decrease in CVD events disappeared in patients who stopped using biological drugs. In that report ${ }^{19}$, it was also emphasized that there was no difference between RA, PsA, and AS in terms of CVD event risk, and that control of systemic inflammation in patients with inflammatory arthritis may reduce the CVD risk. In a study of patients with AS, Bozkirli et al., ${ }^{12}$ determined a significant decrease in the Framingham risk score after 12 weeks of infliximab and associated the cause with a decrease in SBP. In the current study, patients were evaluated in respect of the 10-year CVD risk using the Framingham risk score, and when the 24th week of certolizumab treatment was compared with baseline, there was seen to be a significant reduction in the Framingham risk score in the 24th week. Consequently, it was thought that the decrease in SBP used in the Framingham risk calculations, as well as the increase in HDL-C levels, were effective.

In the BeSt study, which was planned to evaluate the effects of disease activity and anti-rheumatic treatment on $\mathrm{BP}$ in patients with RA, patients initially treated with infliximab were shown to have a lower mean BP than patients treated with DMARDs ${ }^{20}$. In another study, it was claimed that the improvements in microvascular endothelium-dependent functions provided by TNF- $\alpha$ inhibitor therapy might also contribute to a decrease in $\mathrm{BP} .{ }^{21}$ In this study, the decrease in SBP after the certolizumab treatment was associated with improved disease activation, NSAID use was reduced with effective treatment, and there was seen to be increased patient mobility, and improved endothelial function.

Effective anti-inflammatory therapy with TNF- $\alpha$ inhibitory therapy has been shown to reduce the risk of CVD despite increases in lipid levels. ${ }^{17}$ Heslinga et al. ${ }^{22}$ found that TNF- $\alpha$ inhibitory therapy was associated with moderate but broadly parallel increases in TC, LDL-C, and HDL-C, whereas PAI remained unchanged and significant lipid changes after TNF- $\alpha$ inhibitor therapy were only seen in patients with CRP levels $<10$ $\mathrm{mg} / \mathrm{L}$. Similarly, in a study by Mathieu et al. ${ }^{23}, 14$ weeks of TNF- $\alpha$ inhibitor treatment increased TC and HDL-C levels, but there was no significant change in PAI levels. Similarly, in the current study with certolizumab, an increase was determined in TC, HDL-C, and TG levels after 24 weeks of treatment, but no statistically significant change was seen in PAI and LDL-C levels.

A previous study confirmed the significant negative effects of TNF- $\alpha$ on insulin-mediated glucose uptake and the development of IR. ${ }^{24}$ Recently, a rapid and dramatic decrease in serum insulin levels and a rapid improvement in insulin sensitivity have been demonstrated in non-diabetic patients with AS treated with infliximab, which specifically binds to TNF- $\alpha$ with high affinity and neutralizes this cytokine. ${ }^{24}$ In a study of patients with AS and RA by Kiortsis et al. ${ }^{25}$ a significant decrease in HOMAR-IR and an increase in QUICKI were reported after infliximab infusion. With infliximab therapy, a rapid and dramatic decrease in serum insulin levels and a rapid improvement in insulin sensitivity have been shown in patients with AS without DM. ${ }^{26}$ The current study results demonstrated a decrease in HOMAR-IR and insulin level, and an increase in QUCKI after 24 weeks of certolizumab treatment, consistent with studies in the literature. It was thought that the primary effects of the certolizumab treatment were the reduction of possible plasma TNF- $\alpha$ levels and the improvement of endothelial dysfunction by suppressing inflammation.

In this study results also showed a statistically significant decrease in FBG levels. There are conflicting results in the literature in this regard. In a study of patients with AS, PsA, and juvenile idiopathic arthritis, no significant FBG change was observed with three different TNF- $\alpha$ inhibitor drugs at 6 months ${ }^{27}$. In a study by Gonzalez-Gay et al., ${ }^{28}$ although a significant increase in FBG was observed at 120 minutes after infliximab treatment, an improvement in IR was reported. In another study with infliximab in non-DM patients, Miranda-Filloy et al. ${ }^{26}$ observed FBG to be $92.9 \pm 9.2 \mathrm{mg} / \mathrm{dL}$ before infusion and $89.3 \pm 7.4$ 
$\mathrm{mg} / \mathrm{dL}$ after infusion, and a statistically significant decrease in FBG was detected. In the current study, a significant decrease was determined in FBG levels, in parallel with the decrease in IR after 24 weeks of treatment with certolizumab. The possible causes were thought to be a decrease in HOMA-IR and insulin level, an increase in QUCKI levels, improvement of endothelial dysfunction, and a decrease in serum TNF- $\alpha$ levels.

TNF- $\alpha$ expression in adipose tissue is positively correlated with 24-hour energy expenditure and this cytokine has anorexic effects, increases lipolysis, and inhibits adipogenesis. ${ }^{29,30}$ Therefore, TNF- $\alpha$ is more likely to cause cachexia than obesity. In a study of patients with RA and spondyloarthritis (SpA), Luft et al. ${ }^{31}$ showed that some patients $(13.3 \%)$ who received $\mathrm{TNF}-\alpha$ inhibitor treatment developed weight gain of average $5.5 \mathrm{~kg}$ (mean change in BMI $4.7 \mathrm{~kg}$ ). In a recent study of patients with SpA using TNF- $\alpha$ inhibitory therapy, 0.9 $\mathrm{kg}$ of body weight gain over 2 years was demonstrated to be accompanied by a marked increase in visceral adipose tissue after six months, one, and two years. ${ }^{32}$ The data obtained in the current study overlapped with results published in the literature. It can be predicted that the effects of TNF- $\alpha$ inhibitor treatment on weight and body composition could be explained by improvements in the patient's health, an increase in appetite due to control of disease activity, and a decrease in serum TNF- $\alpha$, which has a cachectic effect.

Even though most of the previously published studies on the same subject have been conducted with a similar number of patients, the limitations of this study could be said to be the relatively small number of patients and limited follow-up time. Further studies of larger series with long-term follow-up are needed to confirm these preliminary results of TNF- $\alpha$ inhibitor (certolizumab) therapy on the risk of IR, lipid parameters and CVD in patients with AS.

\section{Conclusions}

TNF- $\alpha$ inhibitor therapy (certolizumab) was associated with a significant increase in HDL-C, TC, and TG levels without any significant change in PAI and LDL-C. Certolizumab therapy increases insulin sensitivity and lowers insulin resistance. There was also a significant reduction in SBP and the 10-year Framingham risk scores at 24 weeks after the start of certolizumab therapy. This risk reduction in CVD is an important finding because the most important cause of death for patients with AS is CVD.

\section{Acknowledgement: None}

Disclosures: The authors have no conflict of interest to declare. This work has not been supported by grant from any funding agency in the public, commercial or not-for-profit sectors.

Data Availability Statement: The data that support the findings of this study are available on request from the corresponding author. The data are not publicly available because of privacy or ethical restrictions.

Author Contributions: All authors have contributed significantly, and all authors agree with the manuscript content. Conception/Design: Hasan Göğebakan, Gözde Yıldırım Çetin; Provision of study materials: Hasan Göğebakan; Collection and/or assembly of data: all authors; Data analysis interpretation: all authors; Manuscript writing: all authors; Final approval of the manuscript: all authors.

\section{References}

1. Sieper J, Braun J, Rudwaleit M, Boonen A, Zink A. Ankylosing spondylitis: An overview. In: Annals of the Rheumatic Diseases . Vol 61. BMJ Publishing Group; 2002:431-432. doi:10.1136/ard.61.suppl_3.iii8

2. Dean LE, Jones GT, MacDonald AG, Downham C, Sturrock RD, Macfarlane GJ. Global prevalence of ankylosing spondylitis. Rheumatology (Oxford) . 2014;53(4):650-657. doi:10.1093/rheumatology/ket387

3. Coates LC, Marzo-Ortega H, Bennett AN, Emery P. Anti-TNF Therapy in Ankylosing Spondylitis: Insights for the Clinician. Ther Adv Musculoskelet Dis . 2010;2(1):37-43. doi:10.1177/1759720X09359728

4. Castañeda S, Nurmohamed MT, González-Gay MA. Cardiovascular disease in inflammatory rheumatic diseases. Best Pract Res Clin Rheumatol . 2016;30(5):851-869. doi:10.1016/j.berh.2016.10.006 
5. Azevedo VF, Pecoits-Filho R. Atherosclerosis and endothelial dysfunction in patients with ankylosing spondylitis. Rheumatol Int . 2010;30(11):1411-1416. doi:10.1007/s00296-010-1416-3

6. Després J-P, Lamarche B, Mauriège P, et al. Hyperinsulinemia as an Independent Risk Factor for Ischemic Heart Disease. N Engl J Med . 1996;334(15):952-958. doi:10.1056/NEJM199604113341504

7. Paolisso G, Valentini G, Giugliano D, et al. Evidence for peripheral impaired glucose handling in patients with connective tissue diseases. Metabolism . 1991;40(9):902-907. doi:10.1016/0026-0495(91)90064-4

8. Sidiropoulos PI, Karvounaris SA, Boumpas DT. Metabolic syndrome in rheumatic diseases: Epidemiology, pathophysiology, and clinical implications. Arthritis Res Ther . 2008;10(3):1-9. doi:10.1186/ar2397

9. Gonzalez-Gay MA, De Matias JM, Gonzalez-Juanatey C, et al. Anti-tumor necrosis factor- $\alpha$ blockade improves insulin resistance in patients with rheumatoid arthritis. Clin Exp Rheumatol . 2006;24(1):83-86.

10. Otten J, Ahrén B, Olsson T. Surrogate measures of insulin sensitivity vs the hyperinsulinaemic- euglycaemic clamp: A meta-analysis. Diabetologia . 2014;57(9):1781-1788. doi:10.1007/s00125-014-3285-x

11. Wilson PWF, D'Agostino RB, Levy D, Belanger AM, Silbershatz H, Kannel WB. Prediction of coronary heart disease using risk factor categories. Circulation . 1998;97(18):1837-1847. doi:10.1161/01.CIR.97.18.1837

12. Ersozlu Bozkirli ED, Bozkirli E, Yucel AE. Effects of infliximab treatment in terms of cardiovascular risk and insulin resistance in ankylosing spondylitis patients. Mod Rheumatol . 2014;24(2):335-339. doi:10.3109/14397595.2013.843752

13. Linden S Van Der, Valkenburg HA, Cats A. Evaluation of Diagnostic Criteria for Ankylosing Spondylitis. Arthritis Rheum . 1984;27(4):361-368. doi:10.1002/art.1780270401

14. Dobiášová M, Frohlich J. The plasma parameter log (TG/HDL-C) as an atherogenic index: Correlation with lipoprotein particle size and esterification rate inapob-lipoprotein-depleted plasma (FERHDL).Clin Biochem . 2001;34(7):583-588. doi:10.1016/S0009-9120(01)00263-6

15. Matthews DR, Hosker JP, Rudenski AS, Naylor BA, Treacher DF, Turner RC. Homeostasis model assessment: insulin resistance and $\beta$-cell function from fasting plasma glucose and insulin concentrations in man.Diabetologia . 1985;28(7):412-419. doi:10.1007/BF00280883

16. Katz A, Nambi SS, Mather K, et al. Quantitative Insulin Sensitivity Check Index: A Simple, Accurate Method for Assessing Insulin Sensitivity In Humans. J Clin Endocrinol Metab . 2000;85(7):2402-2410. doi:10.1210/jcem.85.7.6661

17. Jacobsson LTH, Turesson C, Gülfe A, et al. Treatment with tumor necrosis factor blockers is associated with a lower incidence of first cardiovascular events in patients with rheumatoid arthritis. $J$ Rheumatol . 2005;32(7):1213-1218.

18. Dixon WG, Watson KD, Lunt M, et al. Reduction in the incidence of myocardial infarction in patients with rheumatoid arthritis who respond to anti-tumor necrosis factor $\alpha$ therapy: Results from the British Society for Rheumatology Biologics Register. Arthritis Rheum . 2007;56(9):2905-2912. doi:10.1002/art.22809

19. Lee JL, Sinnathurai P, Buchbinder R, Hill C, Lassere M, March L. Biologics and cardiovascular events in inflammatory arthritis: A prospective national cohort study. Arthritis Res Ther . 2018;20(1):171. doi:10.1186/s13075-018-1669-x

20. Klarenbeek NB, van der Kooij SM, Huizinga TJW, et al. Blood pressure changes in patients with recent-onset rheumatoid arthritis treated with four different treatment strategies: a post hoc analysis from the BeSt trial. Ann Rheum Dis . 2010;69(7):1342-1345. doi:10.1136/ard.2009.124180

21. Sandoo A, Panoulas VF, Toms TE, et al. Anti-TNF $\alpha$ therapy may lead to blood pressure reductions through improved endothelium-dependent microvascular function in patients with rheumatoid arthritis. $J$ Hum Hypertens . 2011;25(11):699-702. doi:10.1038/jhh.2011.36 
22. Heslinga SC, Peters MJ, Ter Wee MM, et al. Reduction of Inflammation Drives Lipid Changes in Ankylosing Spondylitis. J Rheumatol . 2015;42(10):1842-1845. doi:10.3899/jrheum.150193

23. Mathieu S, Dubost JJ, Tournadre A, Malochet-Guinamand S, Ristori JM, Soubrier M. Effects of 14 weeks of TNF alpha blockade treatment on lipid profile in ankylosing spondylitis. Jt Bone Spine . 2010;77(1):50-52. doi:10.1016/j.jbspin.2009.05.012

24. Uysal KT, Wiesbrock SM, Marino MW, Hotamisligil GS. Protection from obesity-induced insulin resistance in mice lacking TNF- $\alpha$ function. Nature . 1997;389(6651):610-614. doi:10.1038/39335

25. Kiortsis DN, Mavridis AK, Vasakos S, Nikas SN, Drosos AA. Effects of infliximab treatment on insulin resistance in patients with rheumatoid arthritis and ankylosing spondylitis. Ann Rheum Dis . 2005;64(5):765766. doi:10.1136/ard.2004.026534

26. Miranda-Filloy JA, Llorca J, Carnero-López B, González-Juanatey C, Blanco R, González-Gay MA. TNF-alpha antagonist therapy improves insulin sensitivity: In non-diabetic ankylosing spondylitis patients. Clin Exp Rheumatol . 2012;30(6):850-855.

27. da Silva BSP, Bonfá E, de Moraes JCB, et al. Effects of anti-TNF therapy on glucose metabolism in patients with ankylosing spondylitis, psoriatic arthritis or juvenile idiopathic arthritis.Biologicals . 2010;38(5):567-569. doi:10.1016/j.biologicals.2010.05.003

28. Gonzalez-Gay M, Gonzalez-Juanatey C, Garcia-Porrua C, Martin J.Anti-Tumor Necrosis Factor-?? Blockade Improves Insulin Resistance in Patients with Rheumatoid Arthritis .; 2014. Accessed March 4, 2020. https://www.researchgate.net/publication/7238490

29. He J, Le DS, Xu X, Scalise M, Ferrante AW, Krakoff J. Circulating white blood cell count and measures of adipose tissue inflammation predict higher 24-h energy expenditure. Eur J Endocrinol . 2010;162(2):275-280. doi:10.1530/EJE-09-0831

30. Batista ML, Peres SB, McDonald ME, et al. Adipose tissue inflammation and cancer cachexia: Possible role of nuclear transcription factors. Cytokine . 2012;57(1):9-16. doi:10.1016/j.cyto.2011.10.008

31. Lutf A, Hammoudeh M. Weight Gain and Hair Loss during Anti-TNF Therapy. Int J Rheumatol . 2012;2012:593039. doi:10.1155/2012/593039

32. Hmamouchi I, Roux C, Paternotte S, Kolta S, Dougados M, Briot K. Early increase of abdominal adiposity in patients with spondyloarthritis receiving anti-tumor necrosis factor- $\alpha$ treatment. $J$ Rheumatol . 2014;41(6):1112-1117. doi:10.3899/jrheum.131150

Table1. Baseline demographic and characteristics of AS patients and control group

\begin{tabular}{llll}
\hline & AS $(\mathbf{n = 8 0})$ & Control $(\mathbf{n = 7 4 )}$ & P-Value \\
\hline Age (years) & $35.05 \pm 7.92$ & $36.49 \pm 12.05$ & 0.455 \\
Gender, Men, n (\%) & $52(65.00)$ & $48(64.80)$ & 0.936 \\
Time Of Diagnosis (months) & $46.41 \pm 70.22$ & - & - \\
Atherogenic index of plasma & $0.151 \pm 0.217$ & $0.074 \pm 184$ & 0.004 \\
Body mass index, kg/m2 & $27.83 \pm 4.12$ & $27.56 \pm 4.08$ & 0.954 \\
Total cholesterol, mg/dL & $175.1 \pm 31.1$ & $174 \pm 30.2$ & 0.645 \\
Triglyceride, mg/dL & $148.7 \pm 52.7$ & $131.6 \pm 38.5$ & 0.000 \\
HDL cholesterol, mg/dL & $43.1 \pm 7.9$ & $47.6 \pm 9.7$ & 0.016 \\
LDL cholesterol, mg/dL & $116.2 \pm 28.1$ & $115.5 \pm 27.4$ & 0.915 \\
Systolic blood pressure, mmHg & $124.2 \pm 12.8$ & $122.4 \pm 11.9$ & 0.837 \\
Diastolic blood pressure, mmHg & $78.8 \pm 11.6$ & $76.7 \pm 10.8$ & 0.158 \\
Uveitis, n (\%) & $12(15.0)$ & - & - \\
Peripheral joint involvement, n (\%) & $17(21.2)$ & - & -
\end{tabular}




\begin{tabular}{llll}
\hline & AS $(\mathbf{n = 8 0})$ & Control $(\mathbf{n = 7 4})$ & P-Value \\
\hline Inflammatory bowel disease, $\mathrm{n}(\%)$ & $6(7.5)$ & - & - \\
\hline
\end{tabular}

Note: Variables are expressed as the mean \pm standard deviation, AS, Ankylosing Spondylitis; HDLcholesterol, high-density lipoprotein cholesterol; LDL- cholesterol, low-density lipoprotein cholesterol.

Tablo 2. Effect on disease characteristics of ankylosing spondylitis patients 24 weeks after certolizumab treatment

\begin{tabular}{llll}
\hline & $\begin{array}{l}\text { Before certolizumab } \\
\text { treatment }\end{array}$ & $\begin{array}{l}\text { After 24 weeks of } \\
\text { treatment }\end{array}$ & P-value \\
\hline BASDAI & $5.79 \pm 1.12$ & $3.28 \pm 0.59$ & 0.000 \\
BASFI & $5,41 \pm 1.25$ & $3.00 \pm 0.60$ & 0.000 \\
AsQoL & $13.12 \pm 1.53$ & $4.52 \pm 1.75$ & 0.000 \\
VASp (cm) & $7.8 \pm 0.7$ & $3.3 \pm 1.2$ & 0.000 \\
Morning Stiffness & $95 \pm 24$ & $18 \pm 11.3$ & 0.000 \\
(minutes) & & $5.5 \pm 0.6$ & 0.000 \\
Modified Schober $(\mathrm{cm})$ & $3.7 \pm 1.1$ & $5.3 \pm 0.9$ & 0.000 \\
Chest Expansion $(\mathrm{cm})$ & $2.9 \pm 0.8$ & $9.4 \pm 4$ & 0.000 \\
ESR, mm/h & $24.4 \pm 9.5$ & $5.2 \pm 3.4$ & 0.000 \\
CRP, mg/L & $13.3 \pm 11.1$ & & \\
\hline
\end{tabular}

Note: Variables are expressed as the mean \pm standard deviation, BASDAI, Bath Ankylosing Spondylitis Disease Activity Index; BASFI, Bath Ankylosing Spondylitis Disease Function Index; ASQoL, Ankylosing Spondylitis Quality of Life Questionnaire; VASp, Visual analogue scale for pain; ESR, erythrocyte sedimentation rate; CRP, C-Reactive Protein.

Tablo 3. Effects of 24-week certolizumab treatment on glucose, HOMA, QUICKI and insulin in patients with ankylosing spondylitis.

\begin{tabular}{llll}
\hline & $\begin{array}{l}\text { Before certolizumab } \\
\text { treatment }\end{array}$ & $\begin{array}{l}\text { After 24 weeks of } \\
\text { treatment }\end{array}$ & P-value \\
\hline $\begin{array}{l}\text { Fasting Blood Glucose, } \\
\text { mg/dL }\end{array}$ & $89.8 \pm 9.3$ & $87.9 \pm 9.2$ & 0.028 \\
HOMA-IR & $2.82 \pm 1.5$ & $2.28 \pm 1$ & 0.014 \\
QUICKI & $0.338 \pm 0.029$ & $0.346 \pm 0.024$ & 0.004 \\
Insüline, mU/L & $12.84 \pm 1.29$ & $10.65 \pm 0.92$ & 0.000 \\
\hline
\end{tabular}

Note: Variables are expressed as the mean \pm standard deviation, HOMA-IR, homeostatic model assessmentinsulin resistance; QUICKI, quantitative insulin-sensitivity check.

Tablo 4. Effect of 24-week Certolizumab treatment on lipid profile and cardiovascular risk factors in patients with ankylosing spondylitis.

\begin{tabular}{llll}
\hline & $\begin{array}{l}\text { Before certolizumab } \\
\text { treatment }\end{array}$ & $\begin{array}{l}\text { After 24 weeks of } \\
\text { treatment }\end{array}$ & P-value \\
\hline $\begin{array}{l}\text { Total Cholesterol, } \\
\mathrm{mg} / \mathrm{dL}\end{array}$ & $175.1 \pm 31.1$ & $180 \pm 30.5$ & 0.000
\end{tabular}




\begin{tabular}{llll}
\hline & $\begin{array}{l}\text { Before certolizumab } \\
\text { treatment }\end{array}$ & $\begin{array}{l}\text { After 24 weeks of } \\
\text { treatment }\end{array}$ & P-value \\
\hline $\begin{array}{l}\text { Triglyceride, mg/dL } \\
\text { HDL cholesterol, }\end{array}$ & $148.7 \pm 52.7$ & $150.7 \pm 50.1$ & 0.024 \\
mg/dL & $43.1 \pm 7.9$ & $45.4 \pm 6.9$ & 0.004 \\
$\begin{array}{l}\text { LDL cholesterol, } \\
\text { mg/dL }\end{array}$ & $116.2 \pm 28.1$ & $117.5 \pm 28.3$ & 0.065 \\
$\begin{array}{l}\text { Atherogenic index of } \\
\text { plasma }\end{array}$ & $0.151 \pm 0.217$ & $0.156 \pm 0.167$ & 0.624 \\
$\begin{array}{l}\text { Systolic blood pressure, } \\
\text { mmHg }\end{array}$ & $124.2 \pm 12.8$ & $121.6 \pm 9.9$ & 0.012 \\
$\begin{array}{l}\text { Diastolic blood } \\
\text { pressure, mmHg }\end{array}$ & $78.8 \pm 11.6$ & $77.6 \pm 9.8$ & 0.254 \\
$\begin{array}{l}\text { Weight, kg } \\
\text { Body mass index, }\end{array}$ & $81.7 \pm 12.6$ & $83.5 \pm 12.1$ & 0.000 \\
kg/m2 & $27.8 \pm 4.1$ & $28.6 \pm 3.8$ & 0.003 \\
$\begin{array}{l}\text { Framingham }(10-Y e a r \\
\text { CVD Risk }\end{array}$ & $4.67 \pm 3.92$ & $3.95 \pm 3.05$ & 0.018 \\
\hline
\end{tabular}

Note: Variables are expressed as the mean \pm standard deviation, HDL-C, high-density lipoprotein cholesterol; LDL-C, low-density lipoprotein cholesterol; CVD, cardiovascular disease.

\section{Hosted file}

tables.docx available at https://authorea.com/users/414766/articles/522710-the-effect-ofcertolizumab-treatment-on-insulin-resistance-lipid-parameters-and-cardiovascular-riskin-patients-with-ankylosing-spondylitis 